\title{
Usinagem
}

\section{Efeitos da adição de níquel em ligas ferro- cromo. Parte II: tempo de vida da ferramenta em processo de torneamento}

\author{
Daniel Cirillo Marques \\ Faculdade de Engenharia Mecânica da Unicamp, Campinas, SP.E-mail: dcirillo@fem.unicamp.br \\ Célia Cristina Moretti Decarli \\ Faculdade de Engenharia Mecânica da Unicamp, Campinas, SP.E-mail: cdecarli@fem.unicamp.br \\ Franco Bubani \\ Faculdade de Engenharia Mecânica da Unicamp, Campinas, SP. E-mail: fbubani@yahoo.es \\ Celso Antonio Barbosa \\ Villares Metals, Sumaré, SP.E-mail: celso.barbosa@villaresmetals.com.br \\ Paulo Roberto Mei \\ Faculdade de Engenharia Mecânica da Unicamp, Campinas, SP.E-mail: pmei@fem.unicamp.br \\ Anselmo Eduardo Diniz \\ Faculdade de Engenharia Mecânica da Unicamp, Campinas, SP.E-mail: anselmo@fem.unicamp.br
}

\section{Resumo}

O objetivo desse trabalho foi estudar a influência do teor de níquel na vida da ferramenta em ligas 18Cr-0,01C0,2Si-0,4Mn (\% em peso) com diferentes teores de níquel $(0,10,20,40$ e $60, \%$ em peso) submetidas à operação de acabamento em torno CNC. Os ensaios foram realizados com pastilhas de metal duro classe M15, revestidas com $\mathrm{TiC} / \mathrm{Al}_{2} \mathrm{O}_{3} /$ TiN. Todas as ligas foram usinadas nas mesmas condições $(\mathrm{Vc}=230 \mathrm{~m} / \mathrm{min}$, ap $=0,6 \mathrm{~mm}$ e $\mathrm{f}=0,1 \mathrm{~mm} / \mathrm{volta}$ ), garantindo, assim, como única fonte de variação, o teor de níquel.

Observou-se que a elevação do teor de níquel diminuiu o tempo de vida útil das pastilhas de corte, o que pode ser devido ao aumento na resistência mecânica a quente $\left(350^{\circ} \mathrm{C}\right)$ das ligas, causado pelo referido elemento. A rugosidade superficial nas ligas austeníticas (10 a $60 \%$ $\mathrm{Ni})$ foi sempre menor que na liga ferrítica $(0 \% \mathrm{Ni})$ e permaneceu praticamente constante durante toda a vida da ferramenta. Na liga ferrítica, os valores de rugosidade aumentaram com o crescente desgaste da ferramenta.

Palavras-chave: Aços inoxidáveis, ligas à base de níquel, desgaste da ferramenta, usinabilidade.

\begin{abstract}
The aim of this work was to study the influence of $\mathrm{Ni}$ content on coated cemented carbide tool wear during the machining process of stainless alloys. For this purpose alloys were prepared with an $18 \% \mathrm{Cr}-0.01 \% \mathrm{C}$ $0.2 \% \mathrm{Si}-0.4 \% \mathrm{Mn}$ base composition and variable $\mathrm{Ni}$ content (0,10, 20, 40 and 60 weight \%). Tests were carried out with coated cemented carbide tools; class M15 with TiC/Al2O3/TiN coating. All alloys were machined under the same process conditions ( $V c=230 \mathrm{~m} / \mathrm{min}, a p=0.6 \mathrm{~mm}$ and $f=0.1 \mathrm{~mm} /$ rotation ), so the only variation source was the Ni content. Preliminary results indicate that the tool life lowers when Ni content rises.
\end{abstract}

Keywords: Stainless steels, Ni alloys, tool wear, tribology, machinability. 


\section{Introdução}

Durante o processamento mecânico de materiais metálicos, tão importantes quanto as propriedades de resistência mecânica, resistência à corrosão etc., são as propriedades da fabricação, como a soldabilidade e a usinabilidade. Produtos planos, por exemplo, freqüentemente, passam por operações de soldagem ou estampagem na fabricação do produto final. Nesse caso, as propriedades de soldagem e estampabilidade são essenciais. Produtos não planos como barras, por outro lado, freqüentemente, passam por operações de usinagem. Estima-se que, anualmente, cerca de 1,5 milhões de toneladas de aço inoxidável sofrem algum tipo de usinagem.

Bons resultados na operação de usinagem estão relacionados com a obtenção de componentes com as dimensões desejadas e qualidade superficial satisfatória. O termo "usinabilidade” é, geralmente, usado para expressar o estado da superfície usinada, a taxa de remoção de material e a facilidade de saída do cavaco ou a vida da ferramenta [1]. A usinabilidade, portanto, não é uma propriedade intrínseca do material, mas, sim, um resultado da interação do material com a operação de usinagem.

A escolha certa do material a ser usinado assim como as ferramentas, fluido de corte, equipamento e condições de usinagem podem trazer vantagens econômicas consideráveis; além disto, podem ser obtidos grandes aumentos de produtividade $[1,2,3]$. Os custos e tempo de produção podem ser, significativamente, reduzidos através da escolha certa dos parâmetros, durante o processamento.

Os aços especiais de alta liga e as ligas à base de $\mathrm{Ni}$, que são objetos desse estudo, são materiais, particularmente, difíceis de usinar, devido às suas características metalúrgicas. Geralmente, a dificuldade de usinagem aumenta com o aumento do teor de elementos de liga e o que se observa é o intenso desgaste das ferramentas com baixa qualidade de acabamento superficial, a péssima característica de saída de cavaco (quebra), cau- sando congestionamento no centro de usinagem e a baixa velocidade de corte levando à baixa produtividade [4] .

A baixa usinabilidade está relacionada com as seguintes propriedades do aço inoxidável austenítico: alta ductilidade e tenacidade (estrutura cúbica de face centrada); alto coeficiente de encruamento; baixa condutividade térmica (causada, principalmente, pelo alto teor de cromo presente nessas ligas, sempre acima de $12 \%$, para garantir a resistência à corrosão) $[5,6,7]$.

Para a usinagem de ligas à base de níquel, normalmente, são utilizadas ferramentas de corte de metal duro, na faixa de velocidades de 10 a $30 \mathrm{~m} / \mathrm{min}$. As superligas à base de níquel têm uma tendência a encruar e retêm a maior parte da força de corte, durante a usinagem. Isto ocasiona calor elevado na interface ferramenta de corte/peça e, conseqüentemente, um maior desgaste da ferramenta de corte. Uma alternativa tem sido o uso de revestimentos, os quais proporcionam aumento na resistência ao desgaste e à deformação da ferramenta de corte [4].

\section{Procedimento experimental}

As ligas utilizadas nesse trabalho foram produzidas pela Villares Metals e a caracterização mecânica encontra-se na primeira parte desse artigo: Efeitos da adição de níquel em ligas ferro-cromo. Parte I: estrutura e propriedades mecânicas.

Os corpos-de-prova para os ensaios de usinagem foram confeccionados a partir das barras recebidas, com diâmetro de $52 \mathrm{~mm}$ e comprimento de $100 \mathrm{~mm}$. Para fixação dos corpos-de-prova foi feita uma "pega” com diâmetro de 29 mm e contra-ponto na extremidade oposta. Os corpos-de-prova foram usinados até um diâmetro final de 30,4 mm.

Os ensaios de usinagem foram realizados em um torno CNC da marca Romi, modelo Galaxi 20, com potência de 15kW, e rotação máxima do eixo árvore de 4500 rpm. Os parâmetros de ensaio utilizados foram: avanço (f) 0,1 mm/rotação; profundidade de corte (ap) 0,6 mm e velocidade de corte (Vc) 230 m/minuto. Usouse um critério para estabelecer o fim de vida da ferramenta, padronizando-se um valor igual a $0,3 \mathrm{~mm}$ para o desgaste de flanco (Vb).

As ferramentas de corte utilizadas foram pastilhas de metal duro revestidas CNMG 120404-MF 2015, classe M15, que foram montadas em um suporte DCLNR 2525M12, com a seguinte geometria do conjunto: ângulo de posição $(\chi)$ 95; ângulo de saída $(\gamma)-6^{\circ}$; ângulo de folga $(\alpha)$ $6^{\circ}$; ângulo de ponta $(\varepsilon) 80^{\circ}$ e ângulo de inclinação $(\lambda)-6^{\circ}$. As pastilhas foram cedidas pela Sandvick do Brasil. O fluido de corte utilizado foi um óleo vegetal emulsionável VASCO1000 com concentração de $10 \%$, direcionando o fluxo para a superfície de saída da ferramenta.

Durante o processo de usinagem, foram controlados o desgaste de flanco e a rugosidade superficial da peça. $\mathrm{O}$ desgaste de flanco $\left(\mathrm{V}_{\mathrm{B}}\right)$ das pastilhas foi monitorado, utilizando-se um microscópio óptico Leica, acoplado a um computador, através do programa de análise de imagens Global Image. Quando o desgaste chegava a um valor de $0,3 \mathrm{~mm}$, encerrava-se o ensaio. A rugosidade média ( $\mathrm{Ra}$ ) e a rugosidade máxima (Ry) dos corpos-de-prova usinados foram medidas, ao longo dos ensaios, utilizando um rugosímetro portátil Mitutoyo.

Foram realizadas duas réplicas de cada ensaio e avaliados os resultados. Nos casos em que a diferença entre as réplicas era maior que $20 \%$, realizava-se o terceiro ensaio.

\section{Resultados e discussões}

A Figura 1 mostra que a vida da ferramenta tende a diminuir com o aumento da concentração de níquel na liga. Esse resultado era esperado, uma vez que a elevação do teor de níquel aumenta a dificuldade de usinagem [4].

Como se pode observar pela Figura 2, os desgastes nas pastilhas ocorre- 
ram como previsto, sendo que a pastilha utilizada para a liga sem níquel (0Ni) não chegou ao fim de vida $(\mathrm{Vb}=0,3)$, dentro do limite de tempo de usinagem preestabelecido (100 minutos).

Os resultados obtidos indicam que a elevação no teor de níquel aumenta o desgaste da ferramenta, dificultando a usinagem do material. Durante a usinagem, ocorre o aumento da temperatura na região de cisalhamento primária, que, segundo Trent [8], chega a $350^{\circ} \mathrm{C}$. Uma explicação possível seria que o aumento do teor de níquel, ao se elevar o limite de resistência a quente dessas ligas [9], reduziria a vida das ferramentas na usinagem, conforme ilustrado na Figura 3.

As Figuras 4 e 5 mostram as curvas de rugosidade média e máxima, em função do tempo de usinagem, para cada liga ensaiada. Pode-se notar que, entre as ligas com níquel, não existe grande diferença na rugosidade medida e que esse valor tende a se estabilizar com o tempo de corte, o que pode ser devido ao material da liga que fica aderido à aresta de corte, mantendo a geometria da ponta da ferramenta próxima à original. A liga ferrítica $(0 \% \mathrm{Ni})$ apresentou valores mais altos de rugosidade, desde o início do ensaio, e esses valores aumentaram com o crescente desgaste da ferramenta. Os valores de rugosidade mais altos observados para a liga sem níquel podem ser devidos à geometria da ferramenta, uma vez que, com o tempo de usinagem, essa geometria se altera constantemente.

\section{Conclusões}

Para ligas 18Cr-0,01C-0,2Si-0,4Mn (\% em peso) com diferentes teores de níquel $(0,10,20,40$ e 60 , \% em peso) submetidas à operação de acabamento em torno CNC, com pastilhas de metal duro classe M15, revestidas com TiC/ $\mathrm{Al}_{2} \mathrm{O}_{3}$ /TiN, concluiu-se que:

1. A elevação do teor de níquel diminuiu o tempo de vida útil das pastilhas de corte, o que pode ser devido ao aumento na resistência mecânica a quente $\left(350^{\circ} \mathrm{C}\right)$ das ligas causado pelo referido elemento.

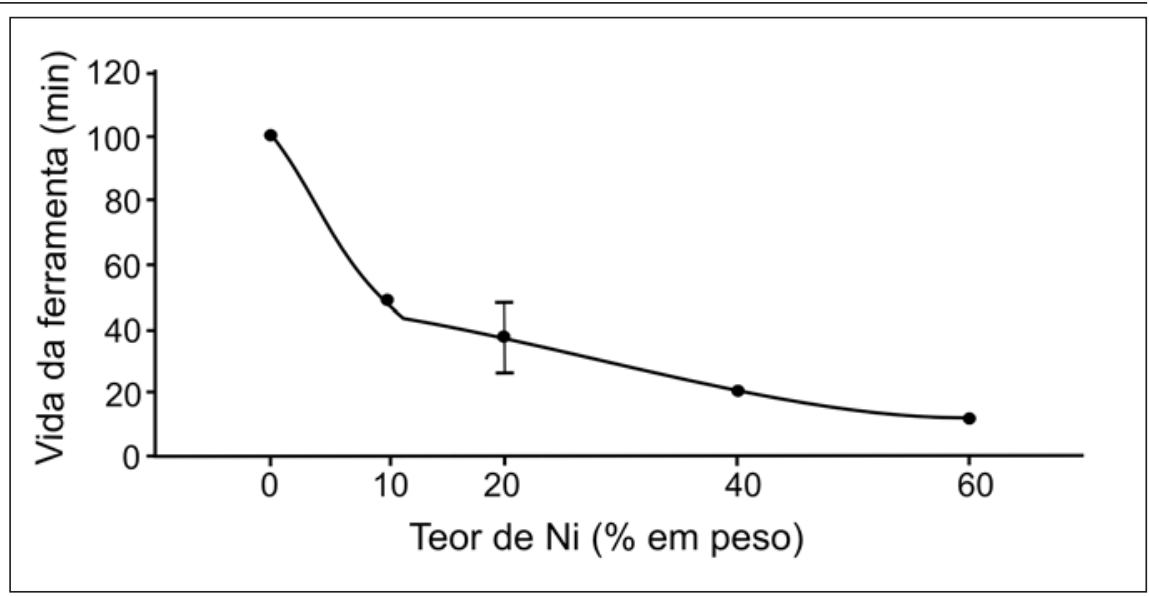

Figura 1 - Tempo efetivo de corte em função do teor de níquel para desgaste de flanco $(\mathrm{Vb})$ igual a $0,3 \mathrm{~mm}$.

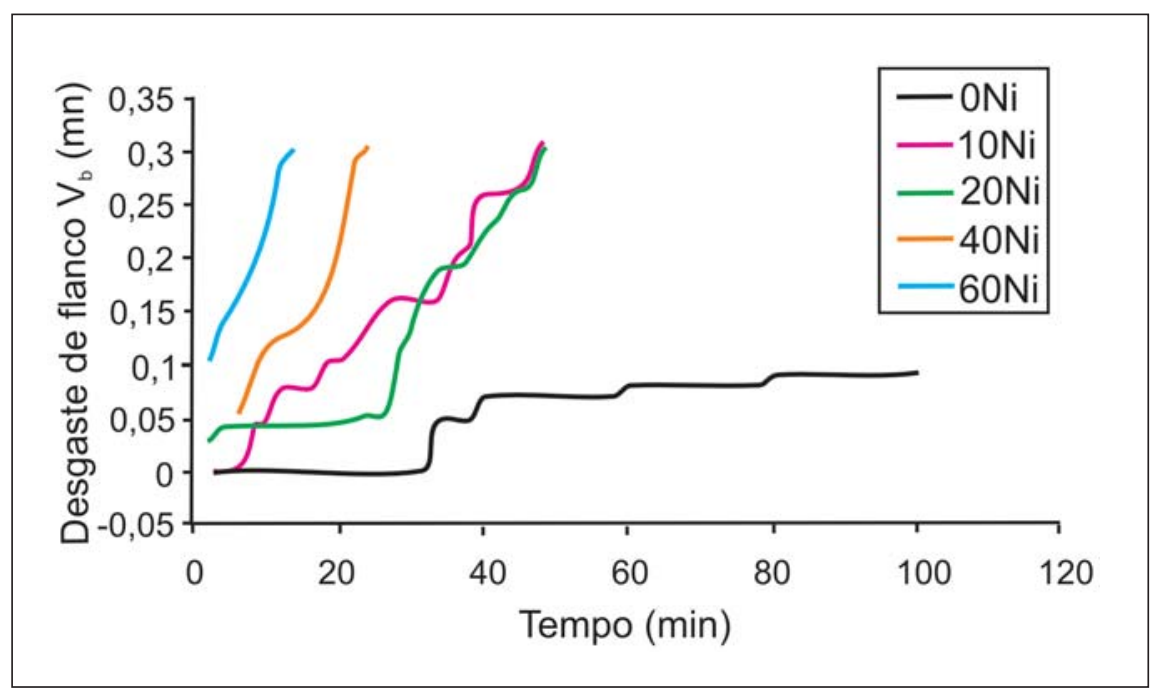

Figura 2 - Desgaste de flanco da ferramenta em função do tempo para as ligas estudadas.

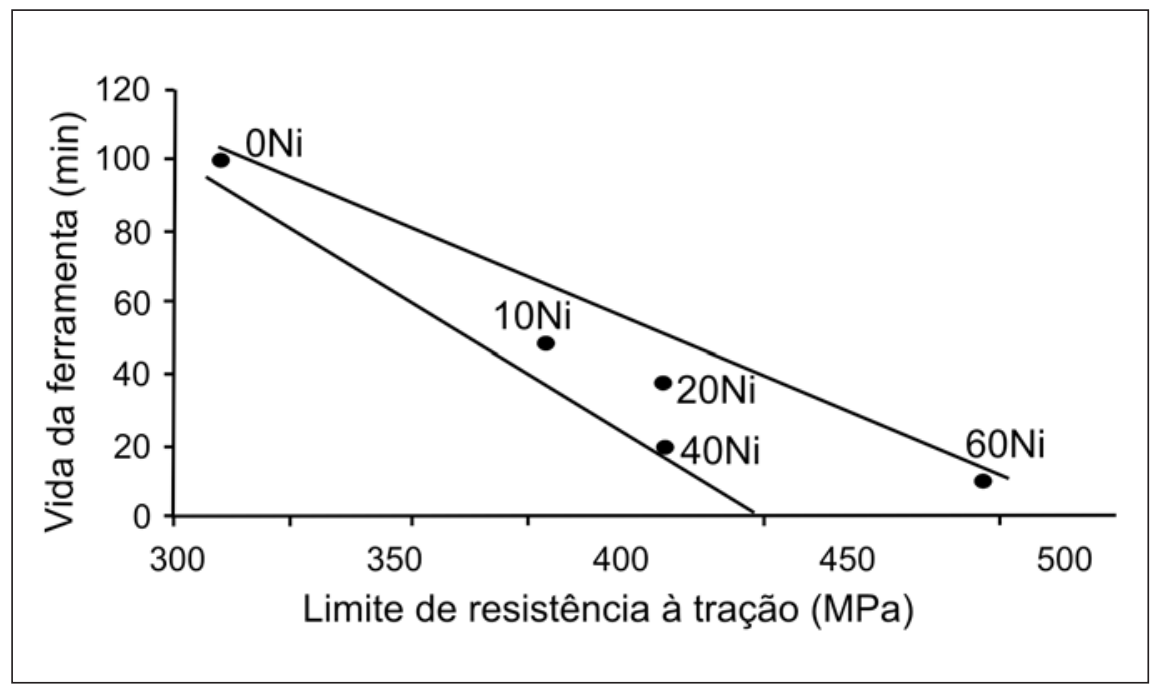

Figura 3 - Tempo de vida da ferramenta em função do limite de resistência à tração a $350{ }^{\circ} \mathrm{C}$ das ligas estudadas. 
2. A rugosidade superficial nas ligas austeníticas (10 a $60 \% \mathrm{Ni})$ foi sempre menor que na liga ferrítica ( $0 \% \mathrm{Ni}$ ), permanecendo praticamente constante durante toda a vida da ferramenta. Na liga ferritica os valores de rugosidade aumentaram com o crescente desgaste da ferramenta.

\section{Agradecimentos}

Ao CNPq e a Villares Metals e Bosch pelo suporte financeiro nesse projeto. Aos técnicos do DEMA e do DEF da Faculdade de Engenharia Mecânica da UNICAMP.

\section{Referências bibliográficas}

1. CHANDRASEKARAN,

H., JOHANSSON, J. O. Chip flow and notch wear mechanisms during the machining of high austenitic stainless steels. CIRP Annals, v. 43, n. 1, p. 101-105, Jan. 1994.

2. BAKER, R. D. Ceramic cutting tools: Application guidelines. Carbide Tool, p. 28-35, 1981.

3. EZUGWU, E. O., MACHADO, A. R., PASHBY, I. R., WALLBANK, J. The effect of high-pressure coolant supply. Lub. Eng., 47, p. 751-757, 1990.

4. EZUGWU, E. O., WANG, Z. M., MACHADO, A. R. The Machinability of Nickel-Based Alloys: A Review. Journal of Materials Processing Technology, 86, p. 1-16, 1999.

5. JANG, D. Y. et al. Surface residual stresses in machined austenitic stainless steel. Wear, v. 194, n. 1-2, p. 168-173, Jun. 1996.

6. KORKUT, I. et al. Determination of optimum cutting parameters during machining of AISI 304 austenitic stainless steel. Materials \& Design, v. 25, n. 4, p.303-305, Jun. 2004.

7. TEKINER, Z., YESILYURT, S. Investigation of the cutting parameters depending on process sound during turning of AISI 304 austenitic stainless steel. Materials \& Design, v. 25, n. 6, p.507-513, Set. 2004.

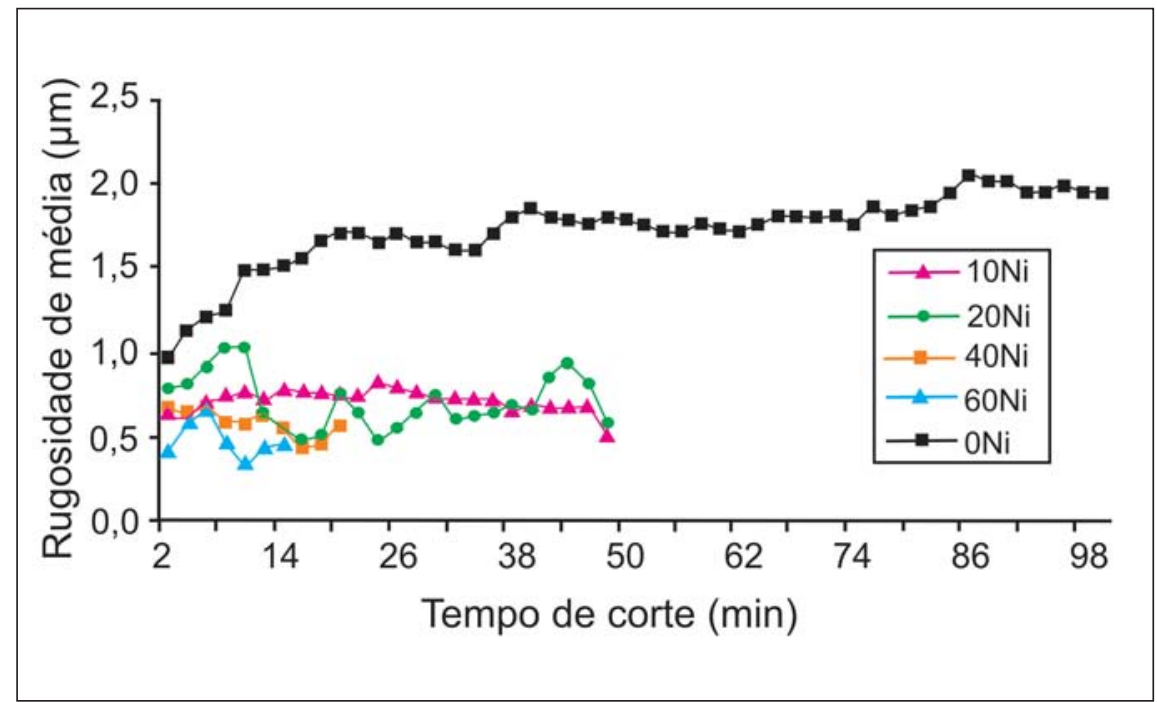

Figura 4 - Rugosidade média (Ra) em função do tempo de corte.

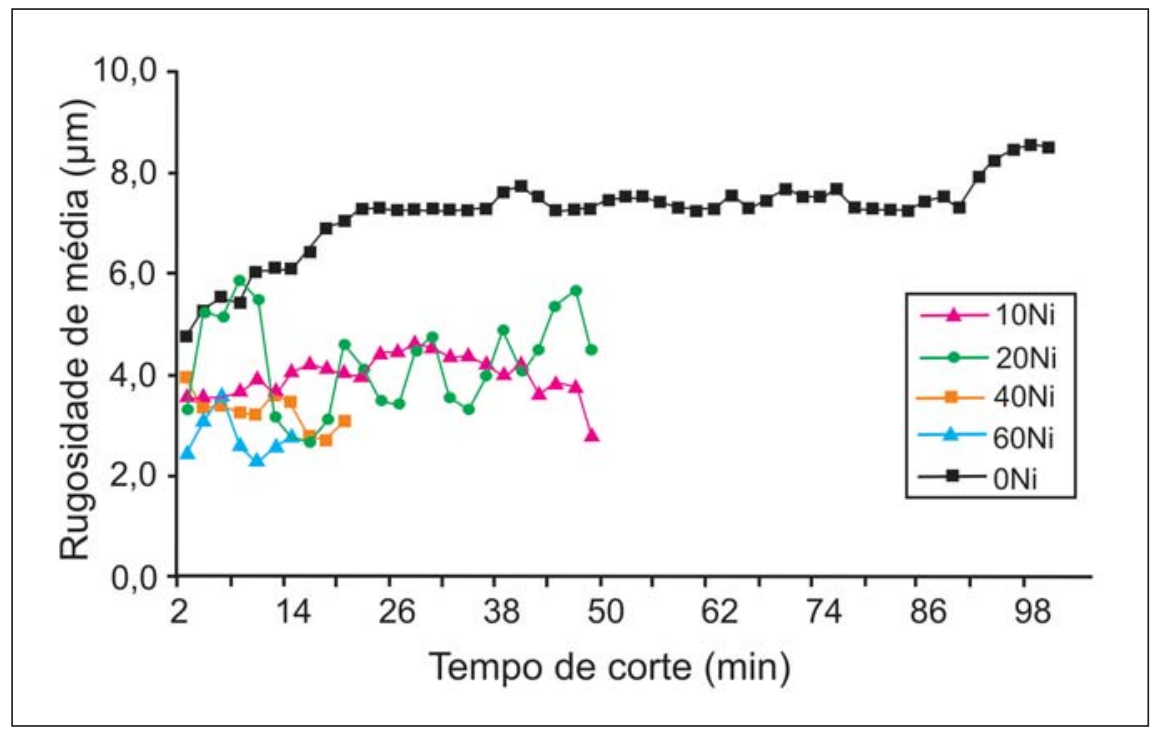

Figura 5 - Rugosidade máxima (Ry) em função do tempo de corte.

8. TRENT, E.M. Metal cutting and the tribology of seizure: III temperature in metal cutting. Wear, v. 128, p. 65-81, 1988.

9. BUBANI, F., DECARLI, C.C.M., MARQUES, D.C., BARBOSA, C.A., DINIZ, A.E., MEI, P.R. Efeitos da adição de níquel em ligas ferro-cromo - Parte I: Propriedades mecânicas. Artigo apresentado no INOX 2006, novembro, São Paulo, 2006.

Artigo recebido em 30/07/2006 e aprovado em 05/10/2006.

$* * * * * *$

Rem - Revista Escola de Minas 71 anos divulgando CIÊNCIA. $* * * * * *$

74 REM: R. Esc. Minas, Ouro Preto, 60(1): 71-74, jan. mar. 2007 